DOI 10.37882/2223-2974.2020.11-2.05

\title{
АНАЛИЗ НАЛОГОВОГО ЗАКОНОДАТЕЛЬСТВА И АРБИТРАЖНОЙ ПРАКТИКИ В ОТНОШЕНИИ НАЛОГА НА ДОБЫЧУ ПОЛЕЗНЫХ ИСКОПАЕМЫХ ПРЕДПРИЯТИЙ ЧЕРНОЙ МЕТАЛЛУРГИИ
}

\section{ANALYSIS OF TAX LEGISLATION AND ARBITRATION PRACTICE CONCERNING THE MINERAL PRODUCTION TAX OF IRON AND STEEL INDUSTRY ENTERPRISES}

\section{A. Klonitskaya \\ A. Potak}

Summary: Taxpayers organize tax planning in order to, on the one hand, optimize tax burden, on the other hand, avoid disincentives to tax evasion. Tax control over the taxpayers activities that use state resources is particularly strictly carried out. The article is devoted to the problem of the tax legislation norms interpretation by taxpayers in calculating the mineral production tax. This article analyses the tax legislation in terms on the tax base calculation procedure for the mineral production tax with a focus on ore mining. The analysis is based on two main problems in calculating the tax: procedure for determination of the mineral estimated value while organizing the extraction of several types of minerals and recognition of normative and actual losses during tax base determination.

Keywords: mineral production tax, Tax Code, tax base, Decision of the Supreme Arbitration Court, direct costs, indirect costs, normative losses, actual losses.

\section{Кэ.н. доцент, Московский авиационньй институт (НИУ)}

Клоницкая Анна Юрьевна

К.э.н., доцент, Московский авиационный институт (НИУ) anna_klonitskaya@mail.ru

Потак Анжелика Гаврииловна

Московский авиационный институт (НИУ) lika_potak@mail.ru

Аннотация: Налогоплательщики организуют налоговое планирование таким образом, чтобы, с одной стороны, оптимизировать налоговое бремя, а с другой - не допустить возникновения признаков ухода от налогообложения. Особенно строго проводится налоговый контроль за деятельностью налогоплательщиков, которые пользуются государственными ресурсами. Статья посвящена проблеме толкования норм налогового законодательства налогоплательщиками при исчислении Налога на добычу полезных ископаемых. В рассматриваемой статье проводится анализ налогового законодательства в части порядка исчисления налогооблагаемой базы для НДПИ с акцентом на добычу руды. За основу для проведения анализа приняты две основные проблемы расчета налога: порядок определения расчетной стоимости полезного ископаемого при организации добычи нескольких видов полезных ископаемых и учет нормативных и фактических потерь при определении налогооблагаемой базы.

Ключевые слова: налог на добычу полезных ископаемых, налоговый кодекс, налогооблагаемая база, Постановление ВАС, прямые расходы, косвенные расходы, нормативные потери, фактические потери.
$\mathrm{B}$ ажнейшим источником пополнения государственного бюджета Российской Федерации являются налоги. Только за пять месяцев 2019 года в консолидированный бюджет поступило 9,5 триллиона рублей, среди которых, около 2,6 триллиона рублей - объём поступлений от налога на добычу полезных ископаемых (НДПИ). [1] Данный налог является относительно новым, порядок его исчисления и уплаты регламентирует глава 26 налогового кодекса.

В соответствии со ст. 334 Главы 26 Налогового кодекса Российской Федерации (НК РФ) организации, осуществляющие добычу полезных ископаемых на основании лицензии на право пользования недрами, подлежат постановке на учет в налоговых органах в качестве налогоплательщика по НДПИ.

При расчете НДПИ полезным ископаемым признается продукция горнодобывающей промышленности и разработки карьеров. Продукция, полученная при дальнейшей переработке (обогащении, техническом переделе) полезного ископаемого, не является объектом обло- жения налога на добычу полезных ископаемых. Об этом сказано в пункте 1 статьи 337 Налогового кодекса РФ. [2]

В связи со спецификой отраслей добывающей промышленности НДПИ является наиболее спорным налогом в части определения и расчета налогооблагаемой базы. Самыми распространенными проблемами, с которыми сталкиваются налогоплательщики НДПИ, являются учет нормативных и фактических потерь при добыче полезного ископаемого, а также распределение расходов между видами полезных ископаемых при определении налогооблагаемой базы исходя из расчетной стоимости полезных ископаемых.

Таким образом, целью данного исследования является анализ действующего налогового законодательства и судебной практики в целях совершенствования правового регулирования порядка определения и исчисления налогооблагаемой базы по НДПИ предприятий черной металлургии на территории Российской Федерации. Актуальность данного исследования обуславливает тот факт, что в окончательном третьем чтении Госдума при- 
няла законопроект о повышении НДПИ в 3,5 раза для металлургов. Таким образом, с 1 января 2021 года вводится рентный коэффициент (К-рента) в размере 3,5 к действующей ставке налога на добычу полезных ископаемых (НДПИ) на ряд твердых полезных ископаемых. [3]

По этой причине наиболее остро перед предприятиями металлургической отрасли стоит проблема определения количества добытого полезного ископаемого и порядок его оценки для целей налогообложения по НДПИ. Очевидно, что грамотный расчёт добытого сырья позволяет не только эффективно вести деятельность, но и оптимизировать налогообложение предприятия с минимальными рисками.

Основным моментом касаемо определения налогооблагаемой базы по НДПИ является то, что она исчисляется налогоплательщиком самостоятельно в отношении каждого добытого полезного ископаемого (в том числе полезных компонентов, извлекаемых из недр попутно при добыче основного полезного ископаемого).

Исходя из этого, в пункте 1 статьи 338 НК РФ описывается следующий порядок определения налогооблагаемой базы: «налоговая база определяется как стоимость добытых полезных ископаемых, рассчитанная в соответствии со статьей 340 настоящего Кодекса, если иное не установлено пунктами 2 и (или) 3 настоящего пункта». [4]

Таким образом, важным элементом обложения налогом на добычу полезных ископаемых является количество добытых полезных ископаемых и порядок определения их стоимости.

Количество добытого полезного ископаемого может определяться прямым или косвенным методом (п. 2 ст. 339 НК РФ). Прямой метод подразумевает расчет количества добытых полезных ископаемых с применением измерительных средств и устройств. Если налогоплательщик использует указанный метод то, количество добытого полезного ископаемого определяется с учетом фактических потерь полезного ископаемого.

В свою очередь, косвенный метод является второстепенным и применяется в тех случаях, когда применение прямого (приоритетного) невозможно.

При использовании косвенного метода определение объема добытого полезного ископаемого происходит расчетным путем на основании данных о содержании добытого полезного ископаемого в общем объеме добытого полезного ископаемого.

Что касается порядка оценки стоимости добытых полезных ископаемых для целей формирования налоговой базы по НДПИ, то налогоплательщикам дается воз- можность определять стоимость самостоятельно исходя из следующих способов (п. 1 ст. 340 НК РФ):

1. исходя из сложившихся у налогоплательщика за соответствующий налоговый период цен реализации без учета субсидий;

2. исходя из сложившихся у налогоплательщика за соответствующий налоговый период цен реализации добытого полезного ископаемого;

3. исходя из расчетной стоимости добытых полезных ископаемых.

Таким образом, применение налогоплательщиком описанных способов, в подпунктах 1 и 2 пункта 1 статьи 340 НК РФ, позволяет произвести оценку стоимости единицы добытого полезного ископаемого исходя из выручки, определяемой с учетом сложившихся в текущем налоговом периоде (а при их отсутствии - в предыдущем налоговом периоде) цен реализации полезного ископаемого. «В случае отсутствия субсидий к ценам реализации добываемых полезных ископаемых налогоплательщик применяет способ оценки, указанный в подпункте 2 пункта 1 настоящей статьи. При этом оценка стоимости единицы добытого полезного ископаемого производится исходя из выручки от реализации добытых полезных ископаемых, определяемой на основании цен реализации с учетом положений статьи 105.3 настоящего Кодекca». [4]

Если же у налогоплательщика не было реализации добытого полезного ископаемого в текущем налоговом периоде, то для определения его стоимости применяется способ оценки, указанный в подпункте 3 пункта 1 статьи 340 НК РФ. При этом стоит обратить внимание, что расчетная стоимость добытого полезного ископаемого в этом случае определяется налогоплательщиком самостоятельно на основании данных налогового учета и применяется тот порядок признания доходов и расходов, который он применяет для определения налоговой базы по налогу на прибыль организаций. При определении расчетной стоимости прямые расходы, произведенные налогоплательщиком в течение налогового периода, распределяются между добытыми полезными ископаемыми и остатком незавершенного производства на конец налогового периода, а косвенные - между затратами на добычу полезных ископаемых и затратами на иную деятельность налогоплательщика пропорционально прямым расходам, относящимся к добыче полезных ископаемых, в общей сумме прямых расходов.

Таким образом, стоимость единицы добытого полезного ископаемого может быть рассчитана по формулам (1), (2), (3):

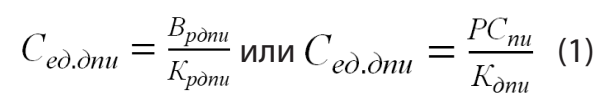

где $C_{\text {ед.дпи }}$ - стоимость единицы добытого полезного 
ископаемого;

$B_{\text {рдпи }}$ - выручка от реализации добытого полезного ископаемого;

$K_{\text {рдпи }}$ - количество реализованного добытого полезного ископаемого;

$P C_{n u}$ - расчетная стоимость полезного ископаемого.

$$
C_{\partial n u}=K_{\partial n u} \times C_{e \partial . \partial n u}(2)
$$

го;

где $C_{\partial п и}$ - стоимость добытого полезного ископаемо-

$K_{\text {дпи }}$ - количество добытого полезного ископаемого.

$$
B_{p n u}=Ц-P_{\partial}(3)
$$
мых;

где $B_{\text {рпи }}$ - выручка от реализации полезных ископае-

Ц - цена без НДС и акциза;

$P_{\partial}$ - сумма расходов по доставке полезного ископаемого.

В соответствии с пунктом 2 статьи 343 НК РФ расчет налога на добычу полезных ископаемых производится ежемесячно по каждому виду полезного ископаемого. Сумма, подлежащая уплате в бюджет, рассчитывается по следующей формуле (4):

$$
\text { НДПИ=Нб } \times \text { Нс (4) }
$$

где Нб - налоговая база (стоимость добытого полезного ископаемого);

Нс - налоговая ставка.

Поскольку НДПИ является достаточно спорным налогом в части определения налогооблагаемой базы, арбитражная практика разрешения споров между налогоплательщиками и налоговыми органами выступает ориентиром для организаций, уплачивающих НДПИ. Далее рассмотрен пример из Российской судебной практики, а именно постановление Высшего Арбитражного Суда Российской Федерации от 29.01.2013 г. № 11498/12.

Дело велось против ПАО «Магнитогорский металлургический комбинат» (далее - общество), заявитель Межрегиональная инспекция Федеральной налоговой службы по крупнейшим налогоплательщикам № 5 (далее - инспекция).

Основанием принятия решения инспекции в части эпизода, касающегося исчисления НДПИ, послужил вывод инспекции о неправомерном уменьшении обществом налоговой базы по этому налогу в связи с занижением стоимости добытых в проверяемом периоде карбонатных пород по металлургии (далее - карбонатные породы) и железной руды (далее - руда).

Как установлено судом, в проверяемый период обществом осуществлялась добыча щебня, реализуемого сторонним потребителям, а также карбонатных пород и руды, используемых полностью в своей производственной деятельности.

При определении налоговой базы по щебню его стоимость оценивалась исходя из сложившихся за соответствующий налоговый период цен реализации (пункт 3 статьи 340 НК РФ).

В связи с отсутствием реализации сторонним потребителям карбонатных пород и руды в целях определения налоговой базы этих видов полезных ископаемых применялся расчетный способ определения их стоимости, предусмотренный пунктом 4 статьи 340 НК РФ.

Расходы, непосредственно связанные с добычей карбонатных пород и руды, общество уменьшало путем перенесения их части на щебень, при определении налоговой базы по которому они не должны учитываться, поскольку оценка стоимости последнего производилась исходя из цен его реализации в соответствии с пунктом 3 статьи 340 НК РФ. В результате налоговая база по карбонатным породам и руде уменьшалась на величину расходов, затраченных на добычу щебня. При этом щебень добывался в объеме, значительно превышающем объемы добычи карбонатных пород и руды.

В данном случае налогоплательщик не учитывал способ оценки стоимости полезных ископаемых и распределял общую величину расходов между видами полезных ископаемых. Однако инспекцией был сделан вывод о том, что следствием применения подобной методики является экономически необоснованное искажение (в сторону уменьшения) налоговой базы по НДПИ, рассчитываемой по карбонатным породам и руде исходя из расчетной стоимости, что привело к уменьшению исчисленного налога на добычу этих полезных ископаемых.[5]

Еще одной распространенной проблемой при исчислении налогооблагаемой базы по НДПИ является учет нормативных и фактических потерь при добыче полезных ископаемых.

Согласно подпункту 1 пункта 1 статьи 342 НК РФ нормативными признаются фактические потери полезных ископаемых при добыче, технологически связанные с принятой схемой и технологией разработки месторождения, в пределах нормативных потерь, утверждаемых в порядке, определенном Постановлением Правительства РФ от 29.12.2001 №921. [6]

Также стоит отметить, что нормативные потери при добыче полезных ископаемых должны утверждаться недропользователями в составе проектной документации, а сами нормативы потерь рассчитываются по конкретным местам их образования при техническом проектировании горных работ. 
В соответствии с положением пп.1 п. 1 статьи 342 НК РФ: «Налогообложение производится по налоговой ставке 0 процентов при добыче: полезных ископаемых в части нормативных потерь полезных ископаемых».[4] При этом, в соответствии со ст. 339 НК РФ, налогоплательщик имеет право определять количество добытого полезного ископаемого прямым, либо косвенным методом. Следовательно, применение 0 ставки в части нормативных потерь правомерно при использовании налогоплательщиком как прямого, так и косвенного метода учета количества добытого полезного ископаемого (Письмо от 22.05.2007 № 03-06-06-01/21). [7]

Однако, как показывает практика, споры по данным нормам достаточно распространены между налогоплательщиками и налоговыми органами, а последние в ряде случаев находят поддержку судей. Так Арбитражный апелляционный суд в Постановлении от 5 марта 2018 г. по делу № A40-100378/2017 между АО «Карельский окатыш» и МИ ФНС России по крупнейшим налогоплательщикам № 5 указал: разночтения сторон по настоящему делу заключаются в том, правомерно ли в рассматриваемой ситуации налогоплательщиком применена ставка 0\% по п. 1 ст. 342 НК РФ с учетом положений ст. 339 и 341 HK РФ.

В соответствии с п.2 ст. 339 НК РФ «...В случае, если определение количества добытых полезных ископаемых прямым методом невозможно, используется косвенный метод».

Было выявлено, что, что метод, которым AO «Карельский окатыш» ведет измерения, необходимые для определения фактических потерь, является косвенным, и основан на использовании расчетной формулы баланса руды и металла (5). Отчет о фактических потерях и засорении составляется один раз в год по установленной статистической форме 70-ТП.

В соответствии сп. 3 ст. 339 НК РФ, если налогоплательщик применяет прямой метод определения количества полезного ископаемого, его количество определяется с учетом фактических потерь полезного ископаемого:

$$
\Pi \Pi и_{\phi}=\Pi и_{\text {расч }}-\Pi И_{\text {доб }}(5)
$$

где $П И_{\text {расч }}$ - расчетное количество полезного ископаемого, на которое уменьшаются его запасы;

ПИ по завершению полного технологического цикла добычи.

Приведенная формула полностью соответствует позиции налогового органа о том, что право на применение ставки 0\% возникает у налогоплательщика в том налоговом периоде (месяце), когда им были одновременно соблюдены следующие условия: а) налогоплательщиком по этому месяцу был заранее осуществлен расчет количества ПИ, которое он планирует добыть (так называемые «плановые, перспективные, оперативные» показатели добычи по определенному налоговому периоду (месяцу));

б) в конце (либо в течение) этого месяца им были осуществлены фактические замеры количества дпи.

Данные значения AO «Карельский окатыш» определял ежегодно, а затем распределял по месяцам методом пропорционального распределения. Решение Арбитражного суда города Москвы от 31.10.2016 указывает на то, что «...позиция Общества в части пропорционального перераспределения объема фактических потерь полезного ископаемого не соответствует нормам налогового законодательства...» [8], а, следовательно, АО «Карельский окатыш имел право применить нулевую ставку НДПИ только в том месяце, когда были подсчитаны годовые потери.

В этой связи трактование норм налогового законодательства организацией AO «Карельский окатыш» представляется некорректным.

Также в п. 2 ст. 339 НК РФ указано то, что в целях исчисления НДПИ под косвенным методом понимается расчетный способ по данным о содержании добытого полезного ископаемого в извлекаемом из недр (отходов, потерь) минеральном сырье.

Расчетная формула баланса руды и металла для определения фактических потерь, связанных с добычей полезных ископаемых (6), обществом закреплена в Инструкции, что не противоречит Постановлению Правительства РФ от 29.12.2001 № 921:

$$
\Pi \Pi И_{\phi}=53-(P M-O)(6)
$$

где ППи ${ }_{\phi}$ - фактические потери полезного ископаемого;

Б3 - погашенные балансовые запасы;

O - засоряющие породы и некондиционные руды

В связи с тем, что положениями ст.339 НК РФ не установлено, при каком методе учета количества добытого полезного ископаемого возможно применение нулевой ставки по НДПИ в части нормативных потерь, можно сделать вывод, что применение данной нормы правомерно как для налогоплательщиков, использующих прямой метод, так и для тех, кто рассчитывает добытые полезные ископаемые косвенным методом.

Позиция Суда в отношении $\mathrm{AO}$ «Карельский окатыш» основана преимущественно на некорректном определении организацией метода пропорционального рас- 
пределения потерь полезного ископаемого.

Безусловно, НДПИ является сложным для исчисления налогом. Это связано в первую очередь, с масштабами добывающих производств и спецификой каждого из них. Для корректного исчисления налогооблагаемой базы налогоплательщику необходимо учитывать не только многочисленные комментарии к статьям 26 главы, но также практику Высшего Арбитражного Суда в спорных вопросах, Постановления Правительства об утверждении нормативов потерь, отраслевые стандарты качества полезного ископаемого для определения стадии обработки, когда НДПИ может быть начислен, письма Минфина в данной области и другие нормативные документы.
Таким образом, оптимизация налогооблагаемой базы по НДПИ без детального учета всех элементов вышеуказанных документов грозит налогоплательщику высокими налоговыми штрафами, пенями и доначислениями.

Подводя итоги исследования, можно сделать вывод, что налоговое законодательство в области НДПИ пока не совершенно и требует доработки в части определения количества и алгоритма оценки стоимости добытого полезного ископаемого, а также его нормативных потерь. Это значительно снизит спорность в вопросах расчета налогооблагаемой базы для предприятий металлургической отрасли и поможет грамотно оптимизировать налоговую нагрузку данного сектора экономики.

\section{ЛИТЕРАТУРА}

1. Кривошапко Ю. Государственный бюджет РФ [Электронный ресурс] // Российская газета. - 2019. - Федеральный выпуск №128 (7886). URL: https://goo.su/2let

2. Налог на добычу полезных ископаемых (НДПИ) [Электронный ресурс] // ФНС Официальный сайт. - URL: https://goo.su/2IF7

3. Госдума повысила в 3,5 раза НДПИ на металлы и минеральные удобрения // Интерфакс. - 2020. - URL: https://goo.su/2if7

4. Налоговый кодекс Российской Федерации (часть вторая) от 05.08.2000 № 117-ФЗ (ред. от 27.12.2019) (с изМ. и доп., Вступ. В силу с 01.01.2020 // НК РФ Глава 26. Налог на добычу полезных ископаемых.

5. Постановление ВАС РФ от 29.01.2013 г. № 11498/12 [Электронный ресурс] // Российский налоговый портал. - URL: https://goo.su/2ieV

6. Постановление Правительства РФ от 29.12.2001 № 921 (ред. от 03.02.2012) "Об утверждении Правил утверждения нормативов потерь полезных ископаемых при добыче, технологически связанных с принятой схемой и технологией разработки месторождения" [Электронный ресурс] // Консультант Плюс. - URL: https://goo.su/2qCq

7. Письмо от 22 мая 2007 года № 03-06-06-01/21 [Электронный ресурс] // Электронный фонд правовой и нормативно-технической документации. URL: https://goo.su/2M0y

8. Постановление от 5 марта 2018 г. по делу № A40-100378/2017 [Электронный ресурс] // Судебные и нормативные акты PФ. - URL: https://g00.su/2LzT 